\title{
COVID 19 Pandemy in Morocco
}

\section{Mohammed Elbiaze*}

Department of Respiratory Diseases, Centre Hospitalier Universitaire Hassan 2 and Laboratory of Epidemiology and Research in Health Sciences, Faculty of Medicine, Mohammed Ben Abdellah University, FES, Morocco

*Corresponding Author: Mohammed Elbiaze, Department of Respiratory Diseases, Centre Hospitalier Universitaire Hassan 2 and Laboratory of Epidemiology and Research in Health Sciences, Faculty of Medicine, Mohammed Ben Abdellah University, FES, Morocco.

Keywords: COVID; Morocco; Fes; Chloroquine; Azithromycin
The 2019-20 coronavirus pandemic was confirmed to have spread to Morocco on 2 March 2020, when the first case COVID-19 case was confirmed in Casablanca. It involved a Moroccan Expatriate residing in Italy and who came from Italy on 27 February 2020. A second case was confirmed by the end of the day, involving an 89-year-old woman Moroccan residing in Italy too who had returned to Morocco on 25 February 2020 from the Italian city of Bologna. As of 30 March 2020, the confirmed cases reached 556, and number of recoveries reached 15 , with a total number of 33 deaths. On 15 March 2020, the suspension of all international flights was decided [1].

On 13 March, the government decided to shut down all schools, effective March 16 until further notice [2]. An e-learning education system is adopted.

A battery of "anticipatory" measures is adopted. This includes the closure of schools and mosques, the banning of gatherings of more than 50 people, the suspension of sea and air links, which will be followed by the confinement and recently the declaration of the state emergency in the country.

Morocco declared a state of medical emergency on March 19, 2020, to take effect on March 20, 2020 at 6:00 pm local time and to remain in effect until April 20, 2020 with possibility to extend for a longer period [3].

The kingdom is implementing World Health Organization (WHO) recommendations to test only suspicious individuals and quarantine them to limit the spread of the virus. A system of identification and contact tracking is adopted.

Chloroquine, and hydroxychloroquine which are manufactured in Morocco, have been validated by the Moroccan Ministry of Health for the treatment of the new coronavirus (Covid-19) on the advice of the technical and scientific committee of the national program for the prevention and control of influenza and acute respiratory infections.
Received: March 31, 2020

Published: May 18, 2020

(C) All rights are reserved by Mohammed

Elbiaze.
Locally, at our university hospital in Fes, we have transformed much of our hospital into COVID areas to accommodate stable patients and reserved intensive care units for serious COVID patients. A training program is carried out for health personnel on individual and collective protection measures and the reception and followup of COVID patients.

A COVID patient management guideline is being finalized. The transfer circuits to Intensive Care Unit and radiology unit is well established. A triage area at the entrance to the hospital allows for the selection of possible cases according to the Ministry of Health's definition. The sample is then taken and the patient is isolated in the area of the suspect patients awaiting the result.

COVID patients confirmed by Polymerase Chain Reaction (PCR) are admitted to COVID services. If there is a worsening, the patient is admitted to intensive care units.

A signaling system isolates COVID patient circuits from other patients' circuit. A protocol for access to the COVID area is standardized according to international recommendations.

The management protocol follows the guidelines of the Ministry of Health. The combination of chloroquine (or hydroxychloroquine) azithromycin is systematic. Healing is declared after the negativation of PCR samples.

Our laboratory is currently conducting in our hospital a study to assess the effect of the combination of chloroquine or hydroxychloroquine and azithromycin in Covid 19 patients confirmed by PCR. Most are asymptomatic or with few symptoms. In our current experience and up to this date, in our Covid unit we follow about 30 patients. Preliminary results show no difference between group of patients who received the combination of chloroquine (or hydroxychloroquine) and azithromycin and those who refused treatment or had adverse effects. The timing of PCR negativation does not appear to be different between the two groups with many adverse effects in treatment group. We particularly noted several cases of digestive disorders, a case of visual hallucinations and a case of palpitations. 


\section{Bibliography}

1. "Morocco suspends all international passenger flights - foreign ministry". Reuters (2020).

2. "Courses Suspended in Morocco from March 16 Until Further Notice". Maghreb Arabe Press (2020).

3. News, Morocco World. "COVID-19: Morocco Declares State of Emergency”. Morocco World News (2020).

\section{Assets from publication with us}

- Prompt Acknowledgement after receiving the article

- Thorough Double blinded peer review

- Rapid Publication

- Issue of Publication Certificate

- High visibility of your Published work

Website: https://www.actascientific.com/

Submit Article: https://www.actascientific.com/submission.php Email us: editor@actascientific.com

Contact us: +919182824667 